\title{
Aplikasi Model Persamaan Struktural dalam Analisis Pengaruh Kualitas Pelayanan (LibQUAL+®) terhadap Kepuasan dan Loyalitas Pemustaka
}

\author{
Iin Irianingsih, Julita Nahar, Ruby Larasati \\ Departemen Matematika, Fakultas MIPA, Universitas Padjadjaran \\ Jl. Raya Bandung Sumedang KM 21 Jatinangor Sumedang 45363 \\ Email: iin.irianingsih@gmail.com, julitanahar@yahoo.co.id
}

\begin{abstract}
ABSTRAK
Model Persamaan Struktural banyak digunakan untuk penelitian di berbagai bidang. Dalam bidang pendidikan, khususnya di perguruan tinggi, perpustakaan adalah salah satu sarana yang sangat dibutuhkan untuk menunjang kegiatan pendidikan, penelitian dan pengabdian pada masyarakat. Dalam paper ini Model Persamaan Struktural diaplikasikan untuk melihat pengaruh kualitas layanan perpustakaan berdasarkan metode LibQUAL+ ${ }^{\circledR}$ terhadap kepuasan penggunanya serta untuk mengetahui bagaimana kepuasan tersebut mempengaruhi loyalitas pengguna perpustakaan FMIPA Universitas Padjadjaran. Hasil yang diperoleh adalah aspek information control paling berpengaruh terhadap kepuasan pengguna perpustakaan. Faktor kepuasan juga sangat berpengaruh terhadap loyalitas pengguna perpustakaan dengan presentase 75,589 \%. Artinya kepuasan pengguna perpustakaan FMIPA Universitas Padjadjaran sangat berpengaruh terhadap faktor loyalitasnya.
\end{abstract}

Kata kunci : Model Persamaan Struktural, LibQUAL+®, kepuasan pemustaka, loyalitas pemustaka.

\begin{abstract}
Structural Equation Modeling is one of important statistical modeling technique. In education, research and community service. In this paper Structural Equation Modeling is applied to observe an effect of the quality of library services with user satisfication based on LibQUAL + ${ }^{\circledR}$ method and to find how that satisfication affects library user loyalty of FMIPA Universitas Padjadjaran. The results are the aspect of information control is the most influence on library user satisfication. The satisfaction factor affects library user loyalty with percentage 75,589\%. It means that user satisfication of FMIPA Universitas Padjadjaran affects library user loyalty.
\end{abstract}

Keywords : Structural Equation Modeling, LibQUAL+®, User's Satisfaction of the Library, User's Loyality of the Library.

\section{Pendahuluan}

Model Persamaan Struktural (SEM) merupakan salah satu teknik analisis multivariat untuk menganalisis hubungan antara variabel laten (variabel yang tidak dapat diukur secara langsung) dengan variabel manifes (variabel yang dapat diukur secara langsung). Model Persamaan Struktural dengan bantuan software banyak digunakan untuk penelitian pada beberapa bidang, seperti pendidikan, pemasaran, sosiologi, kesehatan, psikologi, dan sebagainya. Dalam bidang pendidikan, khususnya di perguruan tinggi, perpustakaan merupakan salah satu sarana yang sangat diperhatikan karena merupakan unsur penunjang dalam kegiatan pendidikan, penelitian, dan pengabdian kepada masyarakat; sebagai fungsi edukasi, sumber informasi, penunjang riset, rekreasi, publikasi, dan interpretasi informasi [3]. Perkembangan dan kwalitas suatu perpustakaan sangat dipengaruhi oleh kepuasan dan loyalitas pemustakanya.

Kualitas layanan perpustakaan akan berpengaruh terhadap kepuasan dan loyalitas pengguna perpustakaan (pemustaka). Kepuasan pemustaka merupakan tingkat kesepadanan antara kebutuhan yang ingin dipenuhi dengan kenyataan yang diterima. Pengguna perpustakaan yang loyal adalah orang yang melakukan kunjungan ulang ke perpustakaan, 
orang yang tetap mengunjungi perpustakaan meskipun ada pengaruh negatif mengenai perpustakaan, serta memberikan informasi yang positif kepada pihak potensial lain dari mulut ke mulut. Kualitas layanan perpustakaan merupakan variabel laten yaitu variabel yang tidak dapat diukur secara langsung. Salah satu metode yang digunakan untuk mengukur kualitas layanan perpustakaan adalah teori LibQUAL+ + . Dimensi kualitas layanan perpustakaan

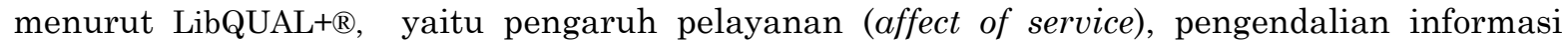
(information control), dan perpustakaan sebagai tempat (library as place) [2].

Pada penelitian ini Model Persamaan Struktural dengan bantuan software LISREL diaplikasikan untuk menganalisis pengaruh kualitas layanan perpustakaan berdasarkan metode LibQUAL+® terhadap kepuasan mahasiswa FMIPA Universitas Padjadjaran yang merupakan salah satu pemustaka serta akan dianalisis apakah faktor kepuasan tersebut mempengaruhi loyalitas pemustakanya.

\section{Metode Penelitian}

Metode yang digunakan dalam penelitian ini adalah metode penelitian survey dengan analisis data primer. Data yang diperoleh berupa data ordinal, yang dikonversi menjadi skala interval menggunakan Method Of Successive Interval. Kemudian dianalisis menggunakan Model Persamaan Struktural dengan bantuan software LISREL.

\subsection{Data Penelitian}

Data Penelitian diperoleh dari hasil kuisioner. Responden penelitian ini adalah mahasiswa S-1 FMIPA Universitas Padjadjaran yang merupakan pengguna perpustakaan (pemustaka) Perpustakaan FMIPA Universitas Padjadjaran. Teknik sampling yang digunakan adalah teknik sampling aksidental. Jumlah data yang terkumpul sebanyak 110 data yang berskala ordinal, yang kemudian dikonversi menjadi skala interval menggunakan Method Of Successive Interval.

\subsection{Variabel Penelitian}

Dalam penelitian ini, metode LibQUAL+ $+\mathbb{R}$ digunakan sebagai pengukur kualitas layanan perpustakaan. Metode LibQUAL+ + dikembangkan dari ServQual yang dirancang untuk mengukur kualitas layanan pada industri jasa. LibQUAL+® dicetuskan pada tahun 1999 oleh para pakar di bidang ilmu perpustakaan dan informasi yang tergabung dalam ARL (Association Research Library) di Amerika Serikat bekerja sama dengan Texas A\&M University, setelah melalui kajian yang lama.

Dimensi kualitas layanan perpustakaan berdasarkan metode LibQUAL+ ${ }^{\circledR}$ adalah sebagai berikut :

1. Affect of Service, yaitu kemampuan, mentalitas, dan sikap petugas perpustakaan dalam melayani pengguna perpustakaan, meliputi:

a. Assurance, yaitu pengetahuan, wawasan, kemampuan, dan keramahan petugas perpustakaan dalam melayani pengguna perpustakaan. Dengan demikian, dapat membuat pengguna perpustakaan menaruh rasa percaya kepada layanan perpustakaan.

b. Emphaty, yaitu rasa peduli dan penuh perhatian petugas perpustakaan kepada setiap pengguna perpustakaan.

c. Responsiveness, yaitu sikap petugas perpustakaan yang selalu siap/tanggap dan membuka diri dalam membantu pengguna perpustakaan yang kesulitan.

d. Reliability, yaitu kemampuan memberikan janji dan harapan dalam pelayanan dan menepatinya secara tepat dan akurat.

2. Library as Place, dimensi ini diambil dari konsep tangibles dalam ServQual, yaitu kemampuan perpustakaan dalam menampilkan sesuatu secara nyata berupa fasilitas fisik (Physical Facilities), bagaimana pemanfaaatan ruang perpustakaan (Utilitarian Space), serta perpustakaan sebagai simbol dan tempat perlindungan (Refuge).

3. Information Control, yaitu menyangkut tentang ketersediaan koleksi yang memadai, kekuatan koleksi yang dimiliki, cakupan isi, kemudahan akses untuk menemukan koleksi, kemudahan navigasi, aktualitas, waktu yang dibutuhkan dalam mendapatkan informasi pada saat dibutuhkan, peralatan, kenyamanan, serta kepercayaan diri. 
Kepuasan merupakan rasa senang atau kecewa seseorang yang muncul setelah membandingkan antara persepsi terhadap kinerja atau hasil suatu produk dengan harapanharapannya [6]. Maka kepuasan adalah fungsi dari persepsi atau kesan atas kinerja dan harapan. Seseorang akan merasa sangat puas jika kinerja atau hasil suatu produk melebihi harapannya, dan akan merasa puas jika kinerja atau hasil suatu produk memenuhi harapannya, tetapi jika kinerja atau hasil suatu produk berada dibawah harapannya maka akan menimbulkan ketidakpuasan/kekecewaan.Berdasarkan metode LibQUAL+® dan konsep kepuasan, indikator kepuasan pengguna perpustakaan:

1. Kepuasan pengguna perpustakaan pada aspek Affect of Service, yaitu perbandingan persepsi pengguna perpustakaan dengan pengharapannya terhadap kinerja petugas perpustakaan dalam hal pelayanan.

2. Kepuasan pengguna perpustakaan pada aspek Library as Place, yaitu perbandingan persepsi pengguna perpustakaan dengan pengharapannya terhadap sarana dan prasarana perpustakaan.

3. Kepuasan pengguna perpustakaan pada aspek Information Control, yaitu perbandingan persepsi pengguna perpustakaan dengan pengharapannya terhadap kualitas informasi dan akses informasi di perpustakaan.

Indikator untuk loyalitas pelanggan adalah Repeat Purchase (kesetiaan terhadap pembelian produk), Retention (ketahanan terhadap pengaruh yang negatif mengenai perusahaan), Referalls (mereferensikan secara total eksistensi perusahaan) [8].

Penerapan dalam loyalitas pengguna perpustakaan, sebagai berikut:

1. Repeat Purchase, pengguna perpustakaan tertarik untuk mengunjungi kembali ke perpustakaan.

2. Retention, pengguna perpustakaan tetap mengunjungi perpustakaan meskipun ada pengaruh negatif mengenai perpustakaan.

3. Referalls, pengguna perpustakaan akan memberikan rekomendasi positif tentang kualitas layanan petugas perpustakaan yang dirasakan sehingga orang lain menjadi tertarik dan terdorong untuk datang ke perpustakaan.

Variabel-variabel penelitian yang digunakan, dapat di lihat pada Tabel 2.1 berikut:

Tabel 2.1. Variabel Penelitian

\begin{tabular}{|c|c|}
\hline Variabel Laten & Variabel Manifes \\
\hline Affect of Service $\left(\xi_{1}\right)$ & $\begin{array}{l}\text { - Assurance }\left(X_{1}\right) \\
\text { - Emphaty }\left(X_{2}\right) \\
\text { - Responsive }\left(X_{3}\right) \\
\text { - Reliability }\left(X_{4}\right)\end{array}$ \\
\hline Library as Place $\left(\xi_{2}\right)$ & 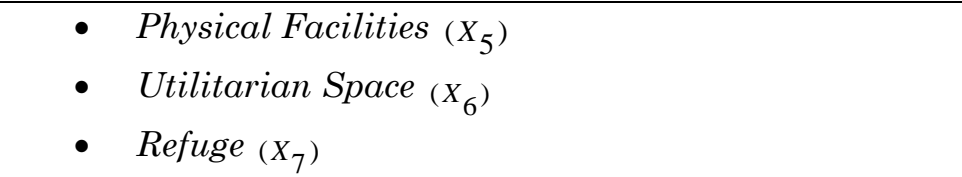 \\
\hline Information Control $\left(\xi_{3}\right)$ & $\begin{array}{ll}\text { - } & \text { Koleksi perpustakaan }\left(X_{8}\right) \\
\text { - } & \text { Kemudahan akses informasi perpusakaan }\left(X_{9}\right) \\
\text { - } & \text { Kepercayaan diri pengguna perpustakaan }\left(X_{10}\right)\end{array}$ \\
\hline $\begin{array}{l}\text { Kepuasan Mahasiswa } \\
\left(\eta_{1}\right)\end{array}$ & 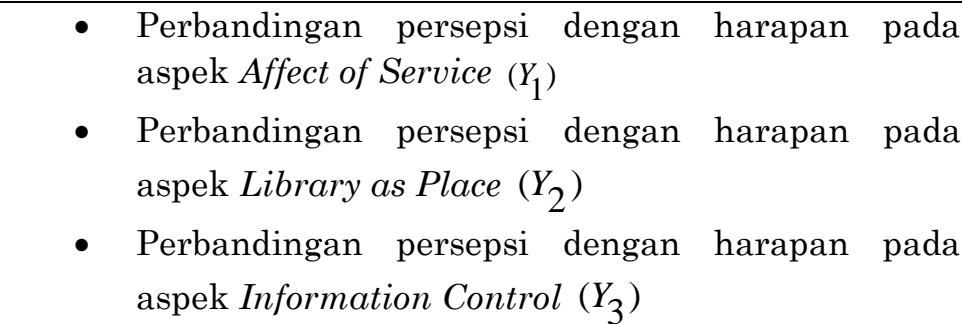 \\
\hline
\end{tabular}




\begin{tabular}{|c|c|}
\hline $\begin{array}{l}\text { Loyalitas } \quad \text { Mahasiswa } \\
\left(\eta_{2}\right)\end{array}$ & $\begin{array}{ll}\text { - } & \text { Repeat Purchase }\left(Y_{4}\right) \\
\text { - } & \text { Retention }\left(Y_{5}\right) \\
\text { - } & \text { Referrals }\left(Y_{6}\right)\end{array}$ \\
\hline
\end{tabular}

\subsection{Model Persamaan Struktural}

Model Persamaan Struktural terdiri atas dua model persamaan, yaitu model struktural dan model pengukuran [5]. Dalam model struktural, diprediksi bagaimana pengaruh variabel laten eksogen terhadap variabel laten endogen, model struktural dirumuskan sebagai berikut:

$$
\boldsymbol{\eta}=\mathbf{B} \boldsymbol{\eta}+\boldsymbol{\Gamma} \boldsymbol{\xi}+\boldsymbol{\zeta}
$$

dengan $\boldsymbol{\eta}$ : vektor variabel laten endogen, $\mathbf{B}$ : matriks koefisien pengaruh variabel laten endogen terhadap variabel laten endogen lainnya, $\Gamma$ : matriks koefisien pengaruh variabel laten eksogen terhadap variabel laten endogen, $\xi$ : vektor variabel laten eksogen, $\zeta$ : vektor kekeliruan pengukuran variabel laten endogen. Sedangkan dalam model pengukuran ditentukan hubungan antara variabel laten dengan variabel manifesnya, model pengukuran dirumuskan sebagai berikut

$$
\begin{aligned}
& X=\Lambda_{x} \xi+\delta \\
& Y=\Lambda_{y} \eta+\varepsilon
\end{aligned}
$$

dengan $\mathbf{X}$ : vektor variabel manifes eksogen, $\boldsymbol{\Lambda}_{\mathbf{x}}$ : matriks faktor loading $(\lambda)$ variabel eksogen, $\boldsymbol{\delta}$ : vektor kekeliruan pengukuran variabel manifes eksogen, $\mathbf{Y}$ : vektor variabel manifes endogen, $\boldsymbol{\Lambda}_{\mathbf{y}}$ : matriks faktor loading $(\lambda)$ variabel endogen, $\boldsymbol{\varepsilon}$ : vektor kekeliruan pengukuran variabel manifes endogen.

\subsection{Tahapan Analisis}

Tahapan analisis Model Persamaan Struktural adalah sebagai berikut:

1. Perumusan model berbasis teori.

Prinsip dasar dalam Model Persamaan Struktural adalah untuk menganalisis hubungan kausal antara variabel eksogen dan endogen sekaligus menguji validitas dan reliabilitas variabel manifes (indikator variabel laten). Pada tahap ini adalah merumuskan model berdasarkan landasan teori yang kuat, dalam penelitian ini menggunakan metode LibQUAL+®.

2. Konstruksi diagram jalur dan model persamaan

Diagram jalur berguna untuk melihat hubungan kausal antara variabel eksogen dan variabel endongen. Hubungan antarvariabel tersebut digambarkan dalam bentuk diagram jalur agar mudah dan jelas untuk dipahami.

Setelah diagram jalur dikontruksi, kemudian mengkonversi diagram jalur tersebut kedalam model persamaan, yaitu model struktural dan model pengukuran.

3. Identifikasi Model

Tahap ini bertujuan untuk memastikan model yang akan diuji bukan merupakan model under-identified, tetapi model just-identified atau over-identified.

Metode untuk identifikasi model adalah derajat kebebasan (degree of freedom) atau ( $d f$ ) yang dirumuskan sebagai berikut:

$$
d f=\frac{1}{2}(p+q)(p+q+1)-t
$$

dengan $p$ : jumlah variabel manifes endogen, $q$ : jumlah variabel manifes eksogen, $t:$ jumlah parameter model yang diestimasi. Jika $d f<0$ maka model dikatakan under-identified. Model dikatakan just-identified jika $d f=0$ dan dikatakan over-identified jika $d f>0$ [6].

4. Pemilihan matriks input dan estimasi parameter model

Matriks yang digunakan dalam penelitian ini adalah, matriks kovarian yang dirumuskan sebagai berikut: 


$$
\begin{aligned}
\Sigma(\theta) & =\left[\begin{array}{cc}
\Sigma_{y y}(\theta) & \Sigma_{y x}(\theta) \\
\Sigma_{x y}(\theta) & \Sigma_{x x}(\theta)
\end{array}\right] \\
& =\left[\begin{array}{cc}
\Lambda_{y}(I-B)^{-1}\left(\Gamma \Phi \Gamma^{\prime}+\Psi\right)\left((I-B)^{-1}\right)^{\prime} \Lambda_{y}^{\prime}+\Theta_{\varepsilon} & \Lambda_{y}(I-B)^{-1} \Gamma \Phi \Lambda_{x}^{\prime} \\
\Lambda_{x} \Phi \Gamma^{\prime}\left((I-B)^{-1}\right)^{\prime} \Lambda_{y}^{\prime} & \Lambda_{x} \Phi \Lambda_{x}^{\prime}+\Theta_{\delta}
\end{array}\right]
\end{aligned}
$$

dengan $\boldsymbol{\Sigma}_{\mathbf{y y}}(\boldsymbol{\theta})$ : matriks kovarians $y, \boldsymbol{\Sigma}_{\mathbf{x x}}(\boldsymbol{\theta})$ : matriks kovarians $x, \boldsymbol{\Sigma}_{\mathbf{x y}}(\boldsymbol{\theta})$ dan $\boldsymbol{\Sigma}_{\mathbf{y x}}(\boldsymbol{\theta})$ : matriks kovarians $x$ dengan $y, \operatorname{Cov}(\zeta): \Psi, \operatorname{Cov}(\boldsymbol{\delta})=\boldsymbol{\Theta}_{\boldsymbol{\delta}}, \operatorname{Cov}(\boldsymbol{\varepsilon}): \boldsymbol{\Theta}_{\boldsymbol{\varepsilon}}, \operatorname{dan} \operatorname{Cov}(\boldsymbol{\xi}): \boldsymbol{\Phi}$.

Metode estimasi parameter model pada penelitian ini adalah metode maximum likelihood, dengan fungsi sebagai berikut

$$
F_{M L}=\log |\boldsymbol{\Sigma}(\boldsymbol{\theta})|+\operatorname{tr}\left(\mathbf{S} \boldsymbol{\Sigma}^{-\mathbf{1}}(\boldsymbol{\theta})\right)-\log |\mathbf{S}|-(p+q)
$$

$\boldsymbol{\Sigma}(\boldsymbol{\theta})$ dan $\mathbf{S}$ masing- masing menunjukkan matriks kovarians model dan matriks kovarians sampel.

5. Evaluasi kecocokan model berdasarkan kriteria goodness-of-fit-test (GFT)

Kecocokan model dievaluasi dengan uji $\chi^{2}$ (Chi Square), Goodness of Fit Test (GFI), dan Root Mean Square Error of Aproximation-on (RMSEA). Model dikatakan fit dengan data apabila nilai $P$-hitung statistik $\chi^{2}$ yang dihasilkan model $\geq 0,05$, nilai $R M S E A<$ 0,08 dan atau nilai $>0,90$ [7].

Modifikasi model dilakukan apabila model yang diusulkan secara empiris tidak fit dengan data. Modifikasi model dilakukan dengan menggunakan metode indeks modifikasi (MI). Nilai MI terbesar menunjukkan penurunan nilai Chi-Square terbesar, sehingga model semakin fit dengan data [1].

6. Interpretasi model

Langkah akhir dalam prosedur Model Persamaan Struktural adalah melakukan interpretasi bilamana model yang dihasilkan sudah fit. Dalam interpretasi model, akan dilihat validitas serta reliabilitas model dengan rumus sebagai berikut

$$
\begin{aligned}
\text { Construct reliability } & =\frac{\left(\sum \lambda_{i}\right)^{2}}{\left(\sum \lambda_{i}\right)^{2}+\sum e_{j}} \\
\text { Variance extracted } & =\frac{\sum \lambda_{i}^{2}}{\sum \lambda_{i}^{2}+\sum e_{j}}
\end{aligned}
$$

$e$ adalah measurement error. Reliabilitas variabel manifes dikatakan baik jika nilai construct reliability $>0,7$ dan nilai variance extracted $>0,5$ [4].

\section{Hasil dan Pembahasan}

Pengolahan Model Persamaan Struktural pada penelitian ini digunakan program LISREL 9.1 Evaluasi model pertama, diperoleh hasil sebagai berikut :

Tabel 3.1 Goodness of Fit Statistics

\begin{tabular}{|l|c|}
\hline Maximum Likelihood Ratio Chi-Square (C1) & $187,99680(P=0,0000)$ \\
\hline Root Mean Square Error of Aproximation (RMSEA) & 0,092349 \\
\hline Goodness of Fit Index (GFI) & 0,82859 \\
\hline
\end{tabular}


maka model tidak fit dengan data. Oleh karena itu perlu dilakukan modifikasi model. Modifikasi model dilakukan dengan menggunakan metode indeks modifikasi (MI). Hasil estimasi modifikasi model dapat dilihat pada Gambar 3.1.

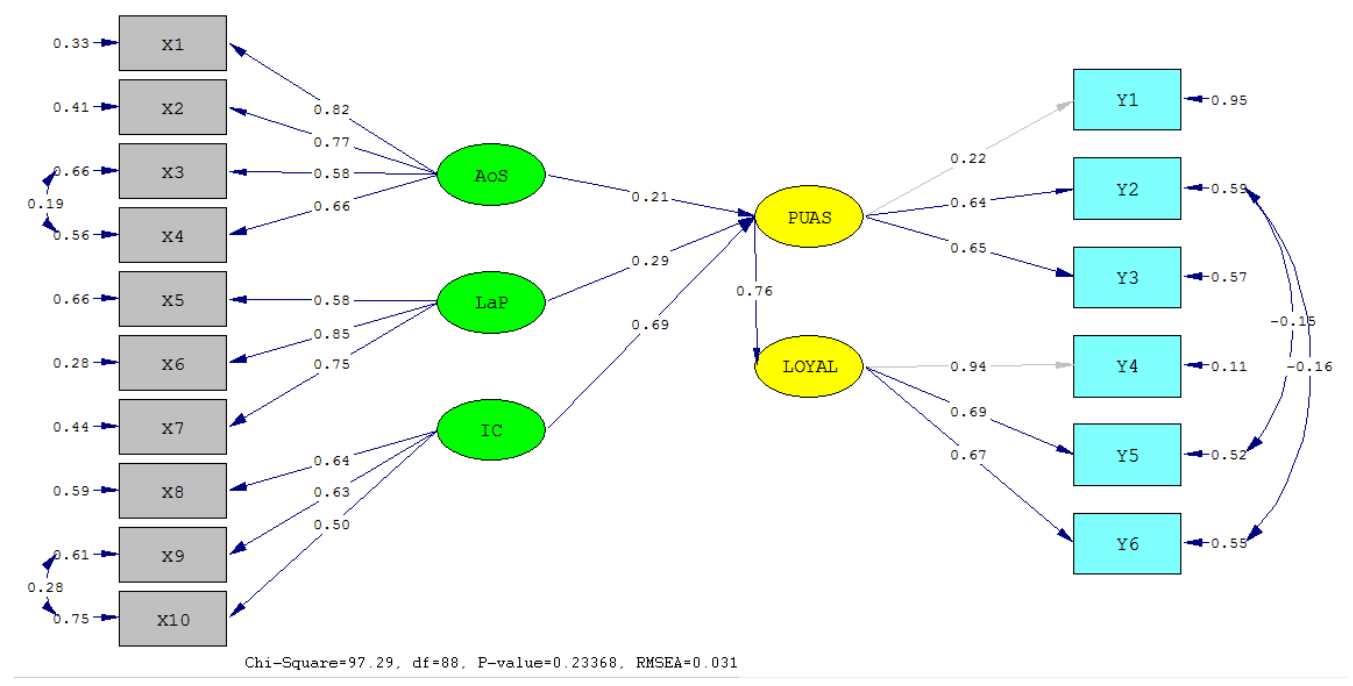

Gambar 3.1. Diagram Jalur Hasil Estimasi Modifikasi Model

Tabel 3.2 Goodness of Fit Statistics Modifikasi Model

\begin{tabular}{|l|c|}
\hline Maximum Likelihood Ratio Chi-Square (C1) & $97,28847(P=0,2337)$ \\
\hline Root Mean Square Error of Aproximation (RMSEA) & 0,030977 \\
\hline Goodness of Fit Index (GFI) & 0,90292 \\
\hline
\end{tabular}

Diperoleh nilai $\chi^{2}$ (Chi Square) dengan derajat kebebasan 88 sebesar 97,28847 dan $P$ bernilai 0,2337. Nilai RMSEA sebesar 0,030977 serta nilai GFI sebesar 0,90292. Maka model fit dengan data.

Setelah mendapatkan model terbaik, selanjutnya akan dijelaskan seberapa besar variabel manifes mampu mengukur variabel latennya (validitas), yang dapat dilihat pada Tabel 2 berikut:

Tabel 3.3. Ukuran Validitas Variabel Manifes Endogen

\begin{tabular}{|c|c|c|}
\hline & Kepuasan & Loyalitas \\
\hline$Y_{1}$ & 0,22013 & \\
\hline$Y_{2}$ & 0,63711 & \\
\hline$Y_{3}$ & 0,65442 & \\
\hline$Y_{4}$ & & 0,94437 \\
\hline$Y_{5}$ & & 0,69131 \\
\hline$Y_{6}$ & & 0,67364 \\
\hline
\end{tabular}

Berdasarkan Tabel 3.3, dapat dijelaskan bahwa variabel $Y_{1}$ mampu mengukur variabel laten kepuasaan sebesar 22,013\%, variabel $Y_{2}$ dan $Y_{3}$ mampu mengukur variabel laten kepuasaan masing-masing sebesar $63,711 \%$ dan $65,442 \%$. Sedangkan variabel $Y_{4}, Y_{5}$, dan $Y_{6}$ mampu mengukur variabel laten loyalitas masing-masing 94,437\%, 69,131\%, dan 67,364\%. Sedangkan untuk validitas variabel manifes eksogen dapat dilihat pada tabel 3.4 berikut. 
Tabel 3.4. Ukuran Validitas Variabel Manifes Eksogen

\begin{tabular}{|c|c|c|c|}
\hline & Affect of Service & Library as Place & Information Control \\
\hline$X_{1}$ & 0,82040 & & \\
\hline$X_{2}$ & 0,77020 & & \\
\hline$X_{3}$ & 0,58310 & & \\
\hline$X_{4}$ & 0,66181 & & \\
\hline$X_{5}$ & & 0,58062 & \\
\hline$X_{6}$ & & 0,85053 & \\
\hline$X_{7}$ & & 0,79094 & 0,63762 \\
\hline$X_{8}$ & & & 0,62628 \\
\hline$X_{9}$ & & & 0,50180 \\
\hline$X_{10}$ & & & \\
\hline
\end{tabular}

Berdasarkan Tabel 3 disimpulkan bahwa variabel manifes $X_{1}, X_{2}, X_{3}$, dan $X_{4}$ masingmasing mampu mengukur variabel laten affect of service sebesar 82,04\%, 77,02\%, 58,31\%, dan $66,181 \%$. Sementara variabel manifes $X_{5}, X_{6}$, dan $X_{7}$ mampu mengukur variabel laten library as place masing-masing sebesar 58,062\%, 85,053\%, dan 79,094\%. Variabel manifes $X_{8}$, $X_{9}$, dan $X_{10}$ mampu mengukur variabel laten information control masing-masing sebesar $63,762 \%, 62,628 \%$, dan 50,18\%.

Selain mengukur validitas variabel manifes terhadap variabel latennya, reliabilitas variabel manifes terhadap variabel latennya juga perlu diukur. Reliabilitas berkaitan dengan konsistensi variabel manifes dalam mengukur variabel latennya. Berikut hasil pengukuran reliabilitas variabel manifes terhadap variabel latennya.

Tabel 3.5. Ukuran Reliabilitas

\begin{tabular}{|c|c|c|}
\hline & Construct Reliability & Variance Extracted \\
\hline Kepuasan & 0,519053635 & 0,29421241 \\
\hline Loyalitas & 0,819266786 & 0,607843995 \\
\hline Affect of Service & 0,804346549 & 0,511067835 \\
\hline Library as Place & 0,782113945 & 0,550713539 \\
\hline Information Control & 0,615280208 & 0,350195314 \\
\hline
\end{tabular}

Berdasarkan Tabel 3.5. variabel laten yang terukur reliabel dengan baik oleh variabel manifesnya adalah Loyalitas, Affect of Service, dan Library as Place. Sementara variabel laten Kepuasan dan Information Control reliabilitasnya terukur kurang baik oleh variabel manifesnya. Setelah mengukur validitas dan reliabilitas variabel manifes terhadap variabel latennya, langkah berikutnya adalah mengukur seberapa besar pengaruh variabel laten terhadap variabel laten lainnya. Berikut nilai koefisien pengaruh variabel laten. 
Tabel 3.6 Koefisien Pengaruh Variabel Laten

\begin{tabular}{|l|c|c|}
\hline & Kepuasan & Loyalitas \\
\hline Affect of Service & 0,21366 & \\
\hline Library as Place & 0,29070 & \\
\hline Information Control & 0,69388 & \\
\hline Kepuasan & & 0,75589 \\
\hline
\end{tabular}

Berdasarkan Tabel 3.6. variabel affect of service mempengaruhi variabel kepuasan sebesar $21,366 \%$, variabel library as place mempengaruhi variabel kepuasan sebesar 29,07\%, dan variabel information control mempengaruhi variabel kepuasan sebesar 69,388\%. Sedangkan variabel kepuasan mempengaruhi variabel loyalitas sebesar 75,589\%.

\section{Simpulan}

Berdasarkan uraian diatas maka dapat diambil simpulan bahwa aspek affect of service, library as place, dan information control masing-masing berpengaruh terhadap kepuasan pengguna perpustakaan FMIPA Universitas Padjadjaran sebesar 21,366\%, 29,07\%, dan 69,388\%, sedangkan loyalitas pengguna perpustakaan FMIPA Universitas Padjadjaran dipengaruhi oleh kepuasan penggunanya sebesar 75,589 \%. Artinya kepuasan pengguna perpustakaan FMIPA Universitas Padjadjaran sangat berpengaruh terhadap faktor loyalitasnya.

\section{Daftar Pustaka}

[1]. Bachrudin, Achmad. 2008. LISREL, LInear Structural RELationship. Jurusan Statistika Universitas Padjadjaran.

[2]. Cook, Colleen \& Maciel, Michael. 2010. A Decade of Assesment at a Research-Extensive University Library Using LibQUAL+®. Research Library Issues 271: A Bimonthly From ARL, CNI, AND SPARC.

[3]. Departemen Pendidikan dan Kebudayaan Dirjen DIKTI. 2004. Perpustakaan Perguruan Tinggi: Buku Pedoman. Jakarta: Jakarta Dirjen Dikti.

[4]. Hair, J.F.Jr., W.C.Black, Babin,B.J, R.E. Anderson, L.Tatham.2006.Multivariate Data Analysis, sixth Edition.New Jersey: Prentice Hall.

[5]. JÖreskog,K \& Sörbon,D.(1996). Lisrel 8:User'Reference Guide.Chicago: Scientific Software International.

[6]. Kotler, Philip. 2003. Manajemen Pemasaran. edisi kesebelas. Jakarta: Indeks Kelompok Gramedia.

[7]. Kusnendi. 2007. Model-model Persamaan Struktural Satu dan Multigroup Sampel dengan LISREL. Bandung: Alfabeta.

[8]. Tjiptono,Fandy.2001.Prinsip-Prinsip Total Quality Service.Yogyakarta: Andi Offset. 